\title{
“ÍTACA" DE ULYSSES EM CINCO VERSÕES AO PORTUGUÊS
}

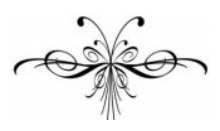

\section{AfONSO TEIXEIRA FILHO}

Resumo: Analisamos aqui as diferentes traduções para o português de um excerto do episódio "Ítaca" do romance Ulysses, de James Joyce. O episódio reproduz, em forma de pastiche e recorrendo a diversas formas de linguagem - inquérito, manual técnico -, a passagem da Odisseia, de Homero, em que Ulisses retorna para casa e a encontra assediada por diversos príncipes que queriam tomar-lhe o reino. Percebe-se, pela análise das traduções, que as posteriores à de António Houaiss (1966) são todas, em maior ou menor medida, tributárias à dele. Percebe-se também que buscaram superar aquilo que acreditavam ser deficiências na tradução de Houaiss. No entanto, nada acrescentaram de novo ao entendimento da obra de Joyce.

Palavras-Chave: Estudos da Tradução; Literatura Comparada; Literatura Irlandesa; Ulysses; James Joyce.

\begin{abstract}
In this essay, we analyze the different translations into Portuguese of an excerpt from the episode "Ithaca", part of the novel Ulysses by James Joyce. The episode is a pastiche and uses various forms of language - police inquiry, technical manual - to represent the passage of Homer's Odyssey, in which Odysseus returns home and find it beset by several princes who wanted to take his kingdom. Analyzing the translations, we can see that all of them derived, to a lesser or greater extent, from Antonio Houaiss' (1966). We also can see that all of them, while trying to overcome what they believed to be deficiencies in Houaiss' translation, added nothing new to the understanding of the work.
\end{abstract}

Keywords: Translation Studies; Comparative Literature; Irish Literature; Ulysses; James Joyce. 
$\mathrm{C}$ oube-nos a tarefa de comparar as diversas traduções para o português de uma passagem do Ulysses, de James Joyce, ${ }^{1}$ a qual tem início na frase "What did Bloom do at the range?" e fim em "faded flowerwater, stagnant pools in the waning moon", no episódio conhecido por Ithaca (ver a passagem completa no início deste dossiê).

As traduções são as seguintes: António Houaiss (Brasil, 1966), ${ }^{2}$ João Palma-Ferreira (Portugal, 1989), ${ }^{3}$ Bernardina da Silveira Pinheiro (Brasil, $2005)^{4}$ e Caetano Galindo (Brasil, 2012) ${ }^{56}$. Essas são as traduções conhecidas no Brasil. No entanto, a primeira tradução do romance foi feita por um galego em $1926^{7}$. Não é apenas a primeira tradução em português, mas a primeira tradução mundial de Ulysses. O autor é Ramón Otero Pedrayo. ${ }^{8}$ Apesar de a tradução contemplar apenas alguns excertos da obra, ela abrange todo o trecho que nos coube analisar. Por isso, reproduzimo-lo junto às demais.

\section{Tradução galega}

Qué mirou Bloom na reixa? Â dereita (máis pequena) penduraba un cazo de porcelana azul; â esquerda (mais longa) unha cazola de ferro negro.

Qué fixo Bloom?

Removeu o cazo â esquerda e levou a cazola

pro fregadeiro pra tapal-a corrente ô abril-o grifo.

Correu a i-auga.

Correu. Do Depósito de Roundwood no condado de Wicklow d'unha capacidade cúbica de 2.400 millós de galos, percorrendo o longor d'un aqüeduto por baixo da terra de filtros principás de simpre e dobre tubería feitos asegún un plan inicial ô coste de 5 pesos por yarda lineal pol-o trayeuto de Dargle, Rathdown, Glen de Downs e Callowhill ô depósito de 26 acres en Stillorgan, unha distanza de 22 millas, e dend'ali ô longo d'un sistema de cada vegada mores tanques, d'unha extension de 250 pés deic'o lindeiro da cibdade na ponte d'Eustace, sobr'a rua Leeson, inda que nos vraus, de moita seca e c un gasto diário de 12 millós e médio de galos, a i-auga tina baixado por baixo do nivel da chea, pol-o que o ispeutor e inxineiro hidráulico Mr. Spencer Harty, C. E. nas instrucciós pr'o emprego da i-auga tina prohibido o gasto das augas municipás pr outros fis dos do consumo (ollando a posibilidade de ter que botar

\footnotetext{
${ }^{1}$ JOYCE, James. Ulysses. Oxford: Oxford University Press, 1998.

${ }^{2}$ JOYCE, James. Ulisses. Trad. de Antonio Houaiss. Rio de Janeiro: Civilização Brasileira, 1982.

${ }^{3}$ JOYCE, James. Ulisses. Trad. de João Palma-Ferreira. Lisboa: Livros do Brasil, 1989.

${ }^{4}$ JOYCE, James. Ulisses. Trad. de Bernardina da Silveira Pinheiro. Rio de Janeiro: Objetiva, 2005.

${ }^{5}$ JOYCE, James. Ulysses. Trad. de Caetano Waldrigues Galindo. São Paulo: Penguin / Companhia das Letras, 2012.

${ }^{6} \mathrm{O}$ excerto de Galindo em exame foi publicado por Scientia Traductionis em 2010, junto de outros cinco excertos, em contraste com o original e com as demais traduções: $<$ http://www.periodicos.ufsc.br/index.php/scientia/article/view/17739/18152>

$<$ http://www.periodicos.ufsc.br/index.php/scientia/article/view/17735/18148>.

${ }^{7}$ Assumimos aqui a tese de que português e galego sejam uma só língua.

${ }^{8}$ PEDRAYO, Ramón Otero. Fragmentos de ulises, 1926. Vigo: Editorial Galaxia, 2003.
} 


\section{“ÍTACA" DE ULYSSES EM CINCO VERSÕES AO PORTUGUÊS}

mau das augas podres dos canles Grande e Royai, coma no 1893), especialmente en Gardas do Hospicio do Sul de Dublin apesar da sua ración de 15 galos diários pra cada probe, tinan sido causantes d'un gasto de 20.000 galos cada noite por unha variante do seu medidor, como demostrou o axente legal da corporación, Mr. Ignatius Rice, procurador, o que era moito en dano da outra porción do pobo que pagaba ben as tasas, solvente, pol-o que díu a voz d'alarma.

Que ademirou Bloom, ollando pro grifo, na i-auga, amante da i-auga, augador, carreteiro d'auga?

A sua universalidade; a sua democrática igualdade e costancia de natureza mirando seu propio nivel; a sua larganza no oceano na proieución de Mercator; a sua fondura nos estreitos da sonda e no Pacífico, que sobe das 8.000 brazas; a inquedanza das augas e movilidade das partículas de superfície, visitando por turno todolos lugares das orelas; a independeza da sua unidade; a variabilidade dos estados da mar; a sua quetude hidrostática na calma; a sua hidrokinética turxididade nas grandes mareas; a sua tranquilidade despois da desvastación; a sua esterilidade nas terras circumpolares; a sua sinificanza climatérica e comercial; a sua preponderanza de 3 a 1 sobra parte enxoita da terra; a sua indisputabre heguemonia estendéndose en légoas cadradas por toda a rexión do trópico de Capricornio; a primordial estabilidade da sua primitiva bacia; o seu leito de trollo leonado; o seu poder pra disolver e manter disoltas todal-as sustanzas que se disolven contando millós de toneladas dos máis finos metás; as suas graciosas erosiós en peninsuas e promontoiros vixiantes do largo; os seus depósitos aluviás; o seu peso, volume e densidade; a sua tranquilidade nos lagos e lagoas das montanas; a gradación das coores nas zonas xeadas, temperás e quentes; as suas ramificaciós conductoras nas correntes dos lagos e na confluência dos grandes rios c as correntes trasoceánecas; gulfstream, correntes norte e sulecuatoriás; a sua forza nos terremotos, manantiales, puzos artesiáns, erupciós, torrenteiras, remoínos, maelstrõms, resacas, regueiros, cachoeiras, olas, puzos das minas, geysers, inundaciós, dioibos, treboadas; a sua estesa circumterrestre e ahourizontal comba; a sua secreción nas primaveiras e humedade latente amostrada pol-os aparellos higrométricos i-eixemprificadas pol-os buratos da parede da porta d'Ashtown, saturación da áer; estilación do orballo; a simpricidade da sua composición, duas porciós de hidróxeno pra unha d'oxíxeno; suas virtudes curativas; a sua densidade no Mar Morto; a sua penetración costante nos canos, fochas, diques malfeitos, buratos do casco dos barcos; as suas propiedás pra crarear, matal-a sede e o lume, mantel-a vexetación; a sua falibilidade coma paradigma e paragón; as suas metamorfoses coma vapor, neboeira, nube, chuvia, orballo, pedrazo, neve; a sua forza en ríxidos hydrantes; a sua variedade de feitios en badías, seos, golfos, fiords, estreitos, albufeiras, attolls, arquipélagos, canles, pasos, esteiros e brazos de mar; a sua solideza en glaziares, ice-bergs, xelos frotantes; a sua homildeza en traballos hidráulicos, muinos, trubinas, dinamos, estaciós eléutricas, serradoiros, fábricas; a sua utilidade en quelles, rios navegabres, docks frotantes; a sua potencialidade derivada das cachoeiras e das mareas; a sua submarina fauna e frora (anacústeca, fotófoba) numéricamentes, senón literalmentes, a verdadeira habitadora da terra; a sua ubicuidade formando o $90 \%$ do corpo do home; a peste das fonduras onde podrecen as herbas na i-auga, doentes frôles da iauga, augas mortas na lua mingoante. ${ }^{9}$

\footnotetext{
${ }^{9}$ Pouco se escrevia galego até a metade do século XIX. Os autores do chamado "rexurdimento", como não dispunham de uma literatura escrita, começaram a escrever adaptando a fala à escrita espanhola e esse procedimento se mantém até hoje, embora muitos linguistas da Galiza já se tenham convencido de que o galego deveria aderir ao Novo Acordo Ortográfico da Língua Portuguesa. Se utilizarmos uma grafia portuguesa para o texto acima, ele não parecerá para nós, falantes do português, tão estranho quanto parece.
} 


\section{AFONSO TEIXEIRA FILHO}

\section{Interpretação}

Qualquer crítica de tradução deve partir da análise do texto como um todo. As particularidades da tradução, os desvios eventuais, as escolhas do tradutor, tudo isso deve ficar para depois. Primeiro, vem a leitura. Expliquemos o texto.

Quando Ulisses retorna da guerra de Tróia e, depois de muitas atribulações, consegue, por fim, chegar a Ítaca, sua cidade, depara-se lá com o assédio de diversos príncipes a ela. Por pensaram que Ulisses houvesse perecido no mar, queriam tomar-lhe o reino exigindo que a viúva dele, Penélope, escolhesse um dos príncipes como esposo.

Diante dessa situação, Ulisses vale-se de uma artimanha, como sempre, pois a artimanha era a sua arte principal. Finge-se de mendigo e elabora um torneio em que o vencedor receberia a mão de Penélope. O resultado é bem conhecido na literatura: um massacre. $\mathrm{O}$ próprio Ulisses vence o torneio, mas, enquanto o disputa, seu filho, Telêmaco, isola o palácio para que os participantes do torneio não tenham como sair dali. Quando Ulisses é reconhecido, mata um a um os pretendentes e retoma sua casa e sua esposa.

Mas, se Ulisses julgou e executou seus adversários, o que ocorreria se ele próprio fosse julgado por ter feito justiça com as próprias mãos? Certamente teria de enfrentar um tribunal com advogados e promotores constituídos. $\mathrm{Na}$ Dublim de 1904, Ulisses é um judeu de origem húngara chamado Leopold Bloom. E terá de ser julgado. ${ }^{10}$

A passagem retratada por Joyce mostra o inquérito de Leopold Bloom, em um capítulo construído por meio de uma série de perguntas, a maior parte delas iniciadas pelo pronome interrogativo what; mais especificamente "what did...":

Ainda que as perguntas pareçam banais, encerram alegorias que remontam, em alguns casos, à Odisseia. E retratam, de maneira epifânica, as angústias da vida mesquinha do dublinense da entrada do século.

A $17^{\mathrm{a}}$ parte do Ulysses de James Joyce foi identificada por Stuart Gilbert, na obra James Joyce's Ulysses - A Study, ${ }^{11}$ como correspondente à passagem da Odisseia em que Ulisses retorna para sua casa, em Ítaca ${ }^{12}$. O massacre que ocorre na Odisseia compara-se à morosidade de um dia qualquer, de uma vida enfadonha, que massacra o homem moderno. ${ }^{13}$ A correspondência é perfeita. Gilbert pôde enxergá-la. Quanto a nós, trataremos de ver se os tradutores de Ulysses a enxergaram também.

\footnotetext{
${ }^{10}$ De acordo com Stuart Gilbert (1969, p. 357), como numa inquisição teológica.

${ }^{11}$ Gilbert, Stuart. James joyce's ulysses - a study. London: Faber \& Faber, 1969.

${ }^{12} \mathrm{O}$ próprio Joyce reconheceu o valor do estudo de Gilbert. Foi o primeiro trabalho a traçar uma correspondência entre os episódios da Odisseia e do Ulysses.

${ }^{13} \mathrm{O}$ mesmo Stuart Gilbert lembra-nos que em capítulo anterior, "Hades", Bloom menciona que sexta-feira é o dia da matança em Dublim. O episódio de Ítaca ocorre nas primeiras horas da sexta-feira, dia 17 de junho.
} 


\section{“ÍTACA" DE ULYSSES EM CINCO VERSÕES AO PORTUGUÊS}

\section{Análise}

A primeira frase é esta: "What did Bloom do at the range?" Houaiss traduziu a frase por "Que fez Bloom ao fogão?" Ferreira, Pinheiro e Galindo o acompanharam. Mas Pedrayo, que não conhecia a de Houaiss, fez diferente: "Qué mirou Bloom na reixa?"

A solução proposta por Houaiss é, ao mesmo tempo, imprecisa e problemática. Imprecisa, pois "range" não é exatamente um fogão. Não é, pelo menos, um fogão como os de hoje. Parece-se mais com os fogões europeus de antigamente, que ficavam sob uma chaminé e que tinham cremalheiras $(h o b)^{14}$. A tradução de Pedrayo é a mais adequada (talvez por ter vivido em uma época em que ainda se usava esse tipo de fogão).

A solução de Houaiss é também problemática porque o termo range indica um alinhamento, uma fileira de objetos; indica também o alcance. $\mathrm{Na} O-$ disseia, o torneio proposto pelo mendigo consistia em atravessar, com uma flechada, o olho de uma série de machados alinhados. ${ }^{15} \mathrm{O}$ termo range, utilizado por Joyce, serve para conotar esse desafio. Estamos certos disso, pois a pergunta seguinte, "Did it flow?", é uma dupla alusão. "Fluiu?" O quê? A flecha fluiu ${ }^{16}$ pelo olho dos machados. E, o sangue dos pretendentes começou a fluir, jorrar. Nenhuma das traduções encontrou solução adequada para isso. A melhor parece ser a de Galindo: "E correu?" (como a de Pedrayo). Mas, mesmo ela, não alude propriamente ao voo da flecha por entre os machados.

À primeira pergunta, veio uma resposta simples. O que Bloom fez foi afastar a caçarola para retirar a chaleira; colocar a chaleira na pia e enchê-la de água. Mas os tradutores complicaram. O parágrafo ficou confuso, ao passo que o original era muito simples. Os próprios tradutores não se entenderam. Apenas Ferreira percebeu que foi Bloom que se levantou e não que tivesse levantado a chaleira. O mesmo entenderam J. M. Valverde (Joyce, 1999, p. 675), ${ }^{17}$ tradutor para o espanhol, e Auguste Morel (Joyce, 1996, p. 954) ${ }^{18}$ tradutor para o francês. ${ }^{19}$ Como a tradução de Morel foi revisada por Larbaud, por Stuart Gilbert e pelo próprio Joyce, é provável que eles e Ferreira estivessem certos ${ }^{20}$.

Outra questão referente à resposta é o vício que os tradutores têm de verter sempre "in order to" (expressão corriqueira) para "a fim de" (expressão pedante). O tradutor galego escreveu simplesmente "pra".

A resposta à pergunta seguinte, "Did it flow?", é prolixa. A água fluiu desde o reservatório, passando por encanamentos e esbarrando na burocracia do

\footnotetext{
${ }^{14}$ É um fogão em que as cremalheiras ficam alinhadas. É bem parecido com um fogão a lenha, mas, na Irlanda, o combustível utilizado era a turfa.

${ }^{15}$ Esse "capítulo" é todo feito em forma de perguntas e respostas. As perguntas são diretas e certeiras como flechas.

${ }^{16} \mathrm{O}$ verbo inglês "to flow" tem o sentido de correr, fluir. Mas "flow" é também a forma antiga de "flew", passado do verbo "to fly", voar. Poderíamos entender a pergunta como "A flecha voou?"

${ }^{17}$ JOYCE, James. Ulises. Traducción J. M. Valverde. Barcelona: Lumen, 1999 [1976].

18 JOYCE, James. Ulysse. Traduction: Auguste Morel. Paris: Gallimard, 1996 [1929].

${ }^{19}$ O tradutor italiano, Giulio de Angelis (JOYCE, 1991, p. 629), usa o termo sollevò (ergueu), com referência ao objeto. JOYCE, James. Ulisse. Traduzione di Giulio de Angelis. Milano: Mondadori, 1991.

${ }^{20}$ E estavam, uma vez que "rose", passado do verbo "to rise", é reflexivo. Se o autor quisesse dizer que Bloom levantara a chaleira, teria usado o verbo "to raise (up)".
} 
departamento de águas. Mas o que Joyce constrói, nessa passagem, é, mais uma vez, uma alusão. Desta vez, uma alusão ao processo de fermentação e destilação do uísque. E também à própria fonte da vida, a água. Porque a palavra uísque deriva do irlandês uisce beathadh [pron. uích-quebá], "água da vida". Mas, literalmente, a passagem descreve em pormenores a planta do sistema de abastecimento de água de Dublim, em $1904^{21}$.

Os tradutores divergiram também quanto ao sentido de "filter mains". As soluções foram "adutoras escoadoras", "canais filtrantes", "condutos de filtro" e "linhas de purificação". O sentido era mais simples e de acepção mais própria à época. Poderíamos traduzir literalmente por "mangas de feltro", ou seja, "coador". É claro que se trata de um sistema de retenção de sujeira. O mais apropriado seria que o tradutor consultasse um manual de engenharia hidráulica, como fez Joyce.

Em seguida, encontramos "initial plant cost", que nada mais é do que "preço de custo". Mas, nas traduções, temos "preço inicial de usina", "custo inicial de fábrica" [aceitável], "custo inicial de planta"22, "custo inicial na planta" ${ }^{\prime 2}$. Depois, temos "22 statute miles", que virou "22 milhas estatutárias", "22 milhas legítimas", "22 milhas estatutárias" [cópia provável da primeira tradução] e "22 milhas-padrão" [aceitável]. Melhor seria "22 milhas regulamentares".

Pouco abaixo, vemos que "sill of the overflow weir" foi traduzido por "peitoril do dique de descarga", "nível das comportas da barragem", "comportas de transbordamento da barragem" e "linha da represa de transbordamento". "Nível de escoamento" ficaria melhor, embora não se veja nessas traduções aquilo que poderíamos reputar como erro, deslize de tradução. $\mathrm{O}$ único problema está na última tradução, pela anfibologia da frase "linha da represa de transbordamento"; é "linha de transbordamento" ou "represa de transbordamento"? Para evitar a anfibologia bastava escrever "linha de transbordamento da represa".

Ainda no mesmo parágrafo, vemos uma alusão a "South Dublin Guardians". Trata-se de uma organização responsável pelos pobres e indigentes da margem sul do rio Liffey. Ela recebia uma cota maior de água para ser distribuída aos pobres, mas teria gasto muito além dessa cota, fazendo com que os que não pagavam pela água recebessem mais do que os que pagavam. Por isso, foi punida. O relatório chama os pagadores de "solvent, sound". A tradução de Galindo parece ser a mais apropriada, "solventes, sólidos", em vez de "solventes, sãos", como as demais. Temos aqui, mais uma vez, uma alusão à Odisseia, na qual os pretendentes consomem todo o vinho da casa de Ulisses. Joyce não está fazendo nenhuma crítica neoliberal à distribuição de água aos pobres, mas, simplesmente, decalcando uma narrativa épica num relatório burocrático. A palavra "solvent" e "sound" o comprovam. "Solvent" se refere mais a líquidos que a finanças, e toda a passagem está falando de água (ou de uísque). "Sound", por sua vez, refere-se também ao barulho, aludindo à algazarra que decorreu da matança dos pretendentes na casa de Ulisses.

\footnotetext{
${ }^{21}$ Essa descrição Joyce retirou do almanaque britânico Thom's Dublin Post Office Directory, de 1904 , relativo ao ano anterior.

${ }^{22}$ Há muitos tradutores no Brasil utilizando o falso cognato "planta" para traduzir o inglês plant ["fábrica"], sobretudo em textos de Economia.

${ }^{23}$ Nesse caso, há uma preocupação com o significante, embora o sentido divirja um pouco do sentido do original.
} 


\section{“ÍTACA" DE ULYSSES EM CINCO VERSÕES AO PORTUGUÊS}

De todas as traduções - ainda que não tenha me detido sobre ela na maior parte das comparações feitas aqui -, a mais admirável é a de Pedrayo, pois ele, diferentemente de qualquer outro tradutor da obra, não se apoiou em nenhuma tradução para fazer a sua e conseguiu, ao meu juízo, lidar muito bem com o texto.

\section{Outras passagens}

What in water did Bloom, waterlover, drawer of water, watercarrier, returning to the range, admire?

Aqui, há uma alusão ao signo de aquário, mas importa saber como os tradutores lidaram com as palavras aglutinadas waterlover, watercarrier. Apenas Galindo verte os dois termos de maneira aglutinante. Houaiss o faz apenas no primeiro termo. Palma-Ferreira e Pedrayo desdobram as aglutinações. E Bernardina Pinheiro, apenas uma.

Its unplumbed profundity in the Sundam trench of the Pacific

Pinheiro e Galindo não traduziram o topônimo. Sundam trench é a fossa de Sonda, que fica na Indonésia, entre as ilhas de Java e Sumatra. Alguns tradutores não costumam traduzir topônimos. Não concordo com essa posição, sobretudo quando se trata de topônimos conhecidos. O maior problema aqui é que Sundam é uma forma inglesa adjetiva.

Artesian wells, eruptions, torrents, eddies, freshets, spates, groundswells, watersheds, waterpartings, geysers, cataracts, whirlpools, maelstroms, inundations, deluges, cloudbursts

Essa passagem reflete as tribulações de Ulisses pelo mar. Mas desconhecer isso não causaria maiores embaraços ao tradutor. É curioso, porém, o fato de Galindo ter usado o termo "tsunâmi", uma palavra japonesa, para traduzir um termo inglês. No entanto, como a passagem nos leva para o extremo-oriente, devido à referência ao estreito de Sonda, utilizar um termo japonês, conhecido em todo o Pacífico, não é despropositado. Galindo foi também o único que manteve "maelström", um termo norueguês, que designa um redemoinho que ocorre nas costas da Noruega. Como esse termo tem relevância na literatura, devido a um conto de Edgar Allan Poe $^{24}$, parece bem justificada sua manutenção.

O texto segue, até ao final do trecho, falando do mar e da água, uma passagem que não apresenta dificuldade para os tradutores, sobretudo para esses tradutores. Traduzir Ulysses não é trabalho para qualquer um.

\footnotetext{
24 “Uma descida no Maelstrom", do livro Contos do grotesco e do arabesco.
} 


\section{Considerações últimas}

As traduções do Ulysses, de Joyce, feitas recentemente no Brasil, ainda que excelentes, pouco acrescentam ao conhecimento e entendimento da obra. $\mathrm{O}$ leitor brasileiro que não tem condições de ler o original não encontrará nessas traduções muito que já não houvesse na tradução pioneira de Antonio Houaiss. O propósito dessas novas traduções foi apresentar um texto menos empolado e de leitura mais fluente para os novos leitores. Dessa forma, preocuparam-se mais em traduzir uma tradução já existente do que o original propriamente dito.

Um ponto, que deve ser considerado quando se trata de traduzir uma obra seminal ou de valor para a história da literatura, é a importância da tradução para o aprimoramento da literatura receptora.

Determinadas traduções, na história da literatura, acabam por ocupar o espaço do original e servem de modelo para as demais traduções. Essa tradução serve de modelo, também, para o próprio original, pois o original passa a ser reinterpretado a partir dela. São feitos que marcam época, realizados no momento histórico adequado, na hora certa. Quando Houaiss realizou a sua tradução, o Brasil e o mundo passavam por uma época de agitações: os movimentos estudantis, a rebeldia da juventude, os hippies; e, no Brasil, a jovem guarda, o tropicalismo, os festivais da canção, a resistência. Houaiss trouxe para o Brasil uma obra de que apenas se ouvira falar. A publicação de Ulisses foi um dos feitos mais relevantes na história do livro no país. Mas essa tradução não foi apenas uma obra realizada em época certa: ela revolucionou o conceito que tínhamos até então da linguagem e, sobretudo, da tradução. Foi, até o momento, a tradução mais audaciosa já feita em língua portuguesa.

As demais traduções de Ulysses perderam o lugar no tempo e no espaço. Quando a tradução de Antonio Houaiss começou a ser lida, os críticos logo se posicionaram para apontar-lhe os erros. De fato, ela continha erros e escolhas questionáveis, mas as melhores traduções são assim. Se os erros e as escolhas questionáveis de Houaiss motivaram as traduções subsequentes, maior erro cometeram seus autores.

De acordo com o crítico Antoine Berman, ${ }^{25}$ a obra de arte não é uma realidade imóvel, estática, imutável, que deve ser reproduzida, mas um lugar de combate entre duas dimensões fundamentais ${ }^{26}$, e a tradução intervém como um momento na vida da obra de arte em que esse combate é reativado. E isso se dá por meio de novas traduções. Elas, porém, tomarão como base, não mais o original, mas aquela tradução que o marcou na literatura receptora. ${ }^{27}$

As novas traduções de Ulysses fundamentam-se todas na tradução pioneira de Houaiss, mas quase nada acrescentam a ela e ao original.

Quando os direitos autorais da obra de Joyce expiraram, em 2011, abriu-se o mercado para novas traduções da obra do escritor. Além da nova tradução, feita por Galindo, surgiram mais duas de Dubliners, uma de Stephen He-

\footnotetext{
${ }^{25}$ BERMAN, Antoine. A tradução e a letra ou o albergue do longínquo. Trad. Mauri Furlan, Marie-Hélène Torres, Andréia Guerini. Rio de Janeiro: 7letras, 2007.

${ }^{26}$ A dimensão do objeto imaginado e a do objeto apreendido pelo leitor. A realidade que cerca o autor e a que cerca o leitor.

${ }^{27}$ BERMAN, 2007, p. 81.
} 


\section{“ÍTACA" DE ULYSSES EM CINCO VERSÕES AO PORTUGUÊS}

ro e já se anuncia outro Ulysses em Portugal ${ }^{28}$. Mas não é por causa disso que se deve fazer uma tradução.

Talvez Ulysses precise, ainda, de outra. Uma tradução que recoloque o romance num plano mais elevado dentro de nossa literatura. Essa tradução deverá ser radical, inovadora e polêmica, e, ao mesmo tempo, manter os mistérios de uma obra cujo pendor é ser misteriosa. Ulysses é uma obra arcana. E assim deveria permanecer nas traduções.

O propósito de uma tradução não é facilitar a compreensão de uma obra. A tradução é apenas uma mudança de código. As complexidades e o mistério que carrega o original devem ser mantidos. E o foram na tradução assinada por Antonio Houaiss.

As outras perderam esse propósito porque perderam o mistério. Perderam também o tempo. Ainda não chegou a hora de se traduzir Ulysses de novo.

Afonso Teixeira Filho

aftefilho@terra.com.br

Doutor, pesquisador da FAPESP

\footnotetext{
${ }^{28}$ Uma das traduções brasileiras de Dubliners saiu pela editora LP\&M e foi traduzida por Guilherme da Silva Braga. O professor José Roberto O'Shea traduziu as outras duas, que foram publicadas pela Siciliano (1992) e Hedra (2012). A nova tradução portuguesa de Ulysses é de Jorge Vaz de Carvalho e deverá sair em 2013.
} 